\section{Public Health} Genomics
Public Health Genomics 2009;12:105-111

DOI: $\underline{10.1159 / 000156114}$
Received: February 26, 2008

Accepted: June 18, 2008

Published online: September 14, 2008

\title{
Genetic Screening: Programs, Principles, and Research - Thirty Years Later
}

\author{
Reviewing the Recommendations of the Committee for the Study of Inborn Errors of \\ Metabolism (SIEM)
}

\section{A.P. Simopoulos}

The Center for Genetics, Nutrition and Health, Washington, D.C., USA

\begin{abstract}
Key Words
Ethical, legal, social, and economic aspects · Genetic counseling $\cdot$ Genetics education · Genetic screening • Public acceptance
\end{abstract}

\begin{abstract}
Screening programs for genetic diseases and characteristics have multiplied in the last 50 years. 'Genetic Screening: Programs, Principles, and Research' is the report of the Committee for the Study of Inborn Errors of Metabolism (SIEM Committee) commissioned by the Division of Medical Sciences of the National Research Council at the National Academy of Sciences in Washington, DC, published in 1975. The report is considered a classic in the field worldwide, therefore it was thought appropriate 30 years later to present the Committee's modus operandi and bring the Committee's recommendations to the attention of those involved in genetics, including organizational, educational, legal, and research aspects of genetic screening. The Committee's report anticipated many of the legal, ethical, economic, social, medical, and policy aspects of genetic screening. The recommendations are current, and future committees should be familiar with them. In 1975 the Committee stated: 'As new screening tests are devised, they should be carefully reviewed. If the experimental rate of discovery of new genetic characteristics means an accelerating rate of appearance of new screening tests, now is the time to develop the medical and social apparatus to accommodate what later on may otherwise
\end{abstract}

turn out to be unmanageable growth.' What a prophetic statement that was. If the Committee's recommendations had been implemented on time, there would be today a federal agency in existence, responsive and responsible to carry out the programs and support research on various aspects of genetic screening, including implementation of a federal law that protects consumers from discrimination by their employers and the insurance industry on the basis of genetic information.

Copyright $\odot 2008$ S. Karger AG, Basel

'Genetic Screening: Programs, Principles, and Research' is the name of the report of the Committee for the Study of Inborn Errors of Metabolism (SIEM Committee) of the National Research Council of the National Academy of Sciences in Washington, DC [1]. The National Research Council SIEM Committee (see Appendix) held its first meeting in August 1972, and its report was completed in 1975. The Committee's report was distributed in 1975 to medical school libraries in the United States, Canada, and elsewhere. It has served as the basis of subsequent studies on genetic screening. The report has received excellent reviews and comments as evidenced by a recent statement [2]: 'This early classic in the field of genetic screening provides an ongoing framework to study the prospects, history, and development of principles, legislation, and program guidelines applicable to genetic testing aims, methodology, and education. Ethical as-

\section{KARGER \\ Fax +4161306 1234 \\ E-Mail karger@karger.ch}

www.karger.com
(C) 2008 S. Karger AG, Basel

$1662-4246 / 09 / 0122-0105 \$ 26.00 / 0$

Accessible online at:

www.karger.com/phg
Artemis P. Simopoulos, MD

The Center for Genetics, Nutrition and Health

2001 S Street, NW, Suite 530

Washington, DC 20009 (USA)

Tel. +1 202462 5062, Fax +1 202462 5241, E-Mail cgnh@bellatlantic.net 
pects are presented from the view of a 'perfect' screener, who would have all relevant facts to provide both errorfree testing and effective counseling, possess a strong sense of the thoughts and emotions of those screened, be as free as possible from self-interest and inappropriate emotionalism, and apply principles consistently.'

The SIEM Committee was commissioned by the Division of Medical Sciences of the National Research Council at the National Academy of Sciences in Washington, DC in response to a letter addressed to the President of the National Academy of Sciences by the Chairman of the Social Issues Committee of the American Society of $\mathrm{Hu}-$ man Genetics in 1972. The letter requested an investigation into the origins, history, and current standing of screening for phenylketonuria and into the effectiveness of its treatment. The Committee was charged to conduct such a survey of phenylketonuria and, in addition, to extend its purview to encompass screening for other genetic diseases and characteristics as well. This aim was interpreted broadly to include a study of the relations between genetics and preventive medicine. The questions to be answered were to what degree genetics has played a part in preventive thinking and practice and how the relationship can be fostered and extended. The Committee held a series of meetings and workshops. Various committee members and staff prepared papers. Experts in economics, ethics, genetics, health education, law, medicine, political science, psychology, and public health were consulted. For certain purposes professionals were employed to gather and analyze data. In addition to evaluating phenylketonuria screening in the United States, the Committee also evaluated the programs in the United Kingdom and Canada. Furthermore, the Committee developed a questionnaire and carried out its own and first ever study on the attitudes of physicians toward genetic screening and also reviewed thoroughly the evolution of laws for phenylketonuria screening in the various states.

Screening, the systematic search in populations for persons with latent, early, or asymptomatic disease, has been going on for many years and has come to be regarded as an appropriate and useful medical practice. Screening programs for genetic diseases and characteristics have multiplied in the last 50 years. In 1975 the Committee stated: 'As new screening tests are devised, they should be carefully reviewed. If the experimental rate of discovery of new genetic characteristics means an accelerating rate of appearance of new screening tests, now is the time to develop the medical and social apparatus to accommodate what later on may otherwise turn out to be unmanageable growth.' What a prophetic statement that was.
As judged by others, the Committee's report is considered a classic [2]. The Committee consisted of outstanding scientists in the medical, legal, economic, social, psychological, ethical, and behavioral aspects of genetic screening. Never before had genetic screening been evaluated and debated so thoroughly over a period of 3 years. Furthermore, the Committee carried out specific studies in order to obtain necessary information. The Committee's Study on the Attitude of Physicians toward Genetic Screening generated data that clearly showed that a positive attitude towards genetic screening on the part of the physician was entirely dependent on the physician's level of knowledge. The success of the Committee's report was due to the fact that the Committee approached its work as a research project. This is reflected in the Committee's title 'for the Study of Inborn Errors of Metabolism'. No other committee or commission since then has been able to carry out such a thorough study on issues involved in genetic screening. Of course operating out of the National Research Council-National Academy of Sciences, the Committee was free of political pressures, which is not the case when committees operate out of the office of the secretary of a government department.

A major contribution of the Committee which continues to receive praise is the 'Proposed Commission to Regulate Screening Practices' and the procedural guidance for the evaluation of a proposed genetic screening program (fig. 1). The Committee's recommendations appear below.

\section{Recommendations}

\section{General}

(1) Genetic screening when carried out under controlled conditions is an appropriate form of medical care when the following criteria are met:

(a) There is evidence of substantial public benefit and acceptance, including acceptance by medical practitioners.

(b) Its feasibility has been investigated, and it has been found that benefits outweigh costs, appropriate public education can be carried out, test methods are satisfactory, laboratory facilities are available, and resources exist to deal with counseling, follow-up, and other consequences of testing.

(c) An investigative pretest of the program has shown that costs are acceptable, education is effective, informed consent is feasible, aims of the program with regard to the size of the sample to be screened, the age of the screenees, 
Fig. 1. Procedure for evaluating a proposed genetic screening program.

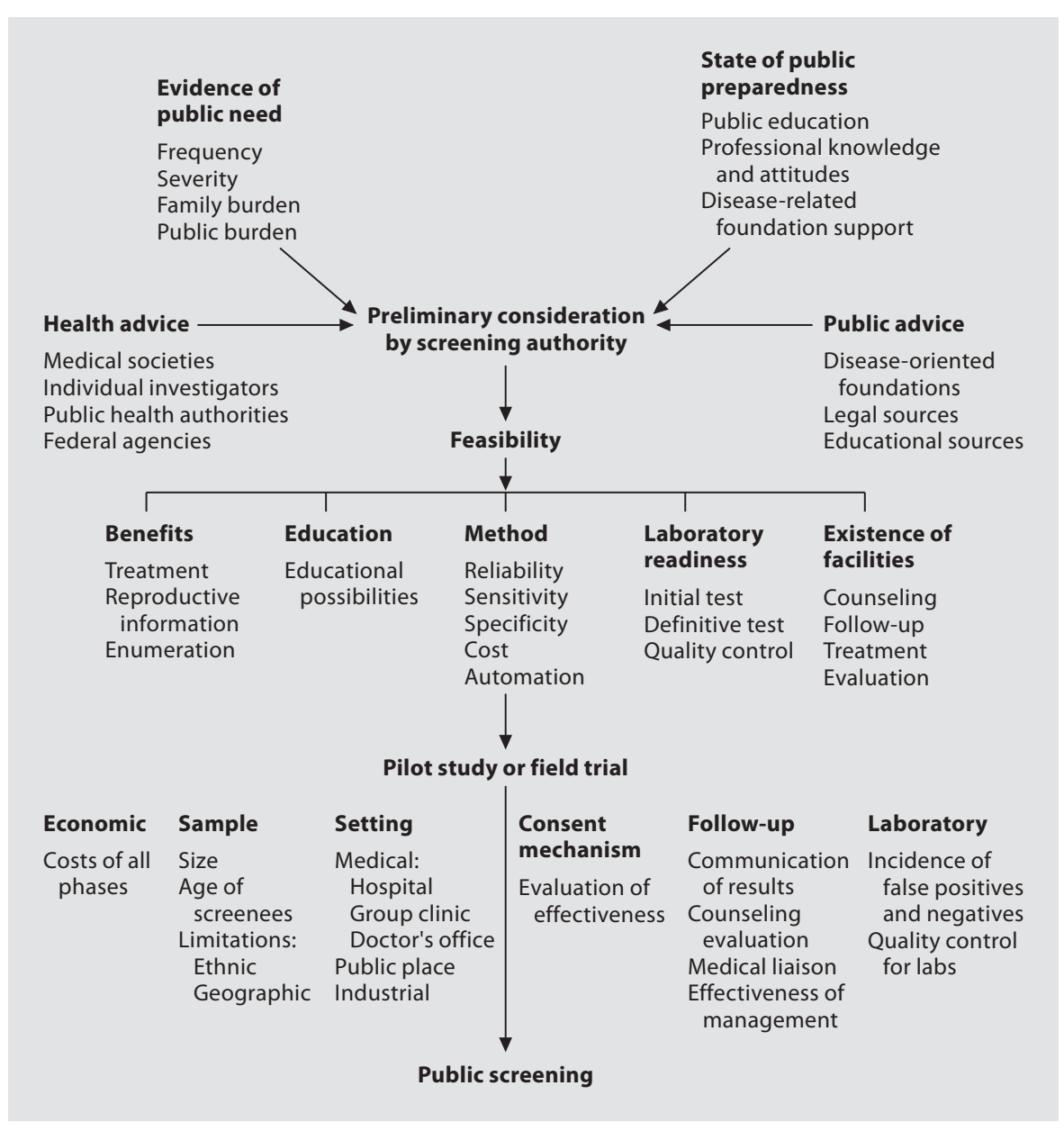

and the setting in which the testing is to be done have been defined, laboratory facilities have been shown to fulfill requirements for quality control, techniques for communicating results are workable, qualified and effective counselors are available in sufficient number, and adequate provision for effective services has been made.

(d) The means are available to evaluate the effectiveness and success of each step in the process.

(2) Screening for phenylketonuria should be continued, and additional studies directed to its improvement should be supported. Although hindsight reveals that screening programs for phenylketonuria were instituted before the validity and effectiveness of all aspects of treatment, including appropriate dietary treatment, were thoroughly tested, current assessment reveals that case finding methods are reasonably efficient, the means for moving from test to definitive management are adequate, and the appropriate dietary treatment is harmless and effective. Experiences in screening for phenylketonuria, both favor- able and adverse, constitute a valuable resource for guidance in the design and operation of future programs. It is important that these experiences be kept in mind and used where appropriate.

\section{Organizational}

(3) Responsibility for the organization and control of genetic screening programs should be lodged in some agency representative of both the public and health professions. This is necessary because of the public nature of genetic screening and its use of public facilities. It is also essential because such screening carries some potential for invasion of privacy, 'labeling', breach of confidentiality, and psychological abuse. The agency might take its authority from local or state government or from regional representation of a federal program.

(4) Public representation is necessary both in determining that a new screening program is clearly in the public interest and also in the design and operation of any such 
program. This is because genetic screening is likely to affect, for one test or another and perhaps for many, every member of the population.

(5) Screening agencies should consult regularly with local medical societies, stimulating their cooperation and participation. This is important in order to give genetic screening the maximum public and professional acceptance.

(6) The aims of genetic screening should be clearly formulated and spelled out by the initiators of any screening program and should be publicly articulated with precision and candor. Thus, there will be no possibility of a mistaken impression that the program is intended to be an instrument of discrimination or is devoted to any 'eugenic' cause.

(7) Some degree of standardization of screening projects is desirable. Demographic diversity, inequality of financial and educational resources of the various states, and the individuality of initiators of screening projects all lead to variation in the design, quality, and cost of screening programs. Standardization might be achieved by some national agency that could act as a clearinghouse for ideas and techniques, set standards, and exert quality control.

(8) Regional programs with laboratories and other facilities based on population numbers rather than political subdivisions should be developed to make screening services of high quality available equally to all. Such programs would avoid the low priority currently given to genetic screening in states of low population density and low budget and would prevent the hardship otherwise suffered by the relatively few persons in such states to whom screening would be beneficial.

(9) In the future, genetic screening should be regarded as one among several preventive health measures and its development should take place in the context of the evolution of health care in general. New projects should be dictated by general principles governing genetic screening rather than by pressures originating in the special qualities of particular diseases.

\section{Educational}

(10) It is essential to begin the study of human biology, including genetics and probability, in primary school continuing with a more health-related curriculum in secondary school because:

(a) In the absence of sufficient public knowledge of human biology and genetics, the difficulties of arousing concern over genetic diseases cannot be overcome, since even longstanding attempts to educate the public regard- ing traditional preventive health measures have had variable success.

(b) In the short run, the educational aspects of genetic screening must consist of special campaigns devoted to each program. Sufficient knowledge of genetics, probability, and medicine leading to appropriate perceptions of susceptibility to and seriousness of genetic disease and of carrier status cannot be acquired as a consequence of incidental, accidental, or haphazard learning.

(11) Screening authorities could improve the effectiveness of public education by studying and employing methods devised and tested by professional students of health behavior and health education. The use of the mass communication media and other techniques to change attitudes and behavior has not been particularly successful, partly because of failures to follow the appropriate precepts.

(12) Continuing education courses for physicians should place emphasis on human genetics and particularly on the practical application of population genetics. In medical schools the study of genetics should be included in courses of epidemiology and preventive medicine, as well as in courses of medicine, pediatrics, and obstetrics. Such emphasis would raise the level of genetic knowledge of physicians and would increase their orientation toward preventive medicine so that they would be able to take an active role in genetic screening.

(13) Schools of medicine, public health and hygiene, and allied health sciences, as well as universities, should receive support for programs to set standards and train persons to inform and counsel participants in screening programs. Such counselors are already in short supply.

\section{Legal}

(14) Participation in a genetic screening program should not be made mandatory by law, but should be left to the discretion of the person tested or, if a minor, of the parents or legal guardian.

(15) Information obtained through genetic screening should not be made available to anyone other than the screenee except with the permission of the screenee or, in the case of a minor, with the permission of the parents or legal guardian.

(16) Screening authorities should consult regularly with lawyers and other persons knowledgeable in ethics to avoid social consequences of screening that may be damaging. These take the form of invasion of privacy, breach of confidentiality, and other transgressions of civil rights, as well as psychological damage resulting from being 'labeled' or from misunderstandings about the significance 
of diseases and carrier states. The usefulness of or need for legislation to protect the participants in screening programs from such dangers should be reviewed from time to time.

(17) For states considering legislation mandating genetic screening, the Committee recommends examination of a law creating a Board on Hereditary Disorders such as that proposed by the Council of State Governments' Committee on Suggested State Legislation.

\section{Research}

(18) Research in genetic screening should be governed by the rigorous standards employed in laboratory investigation. Special efforts should be made to evaluate all aspects, even of routine procedures, and the social and ethical ramifications of screening in the lives of the persons tested should be investigated. So far, experience in genetic screening is insufficient to foresee and forestall all possible untoward side effects. Accordingly, it should be approached in an experimental mood. At present, it is impressions that prevail, rather than data collected and analyzed according to scientific rules.

(19) It is important that screening be used to study the natural history of genetic disorders for which there is no treatment at this time. Such research, in which the object of screening is to discover the full range of expression of the disease, will further the development of new methods of treatment and can provide the control data needed to evaluate proposed treatments. Particular effort must be exerted to protect individuals identified by such screening against the psychological and social hazards that attend all screening programs, but whose impact may be enhanced by the lack of an effective treatment.

(20) Research should be supported in adapting discoveries of new genetic characteristics of screening purposes. This research includes increasing the number and quality of tests, reducing their cost, building regional networks of laboratories and other facilities to broaden and improve service, and designing simple, inexpensive, and effective treatments for newly discovered diseases. The acquisition of genetic knowledge is proceeding exponentially, and much of it is germane to the aims of genetic screening.

(21) Research to discover polymorphic alleles occurring in high frequency should receive more substantial support. Certain common alleles have been shown to be associated with disease, and it is predictable that many more will also be implicated.

\section{Comment}

It is evident that the Committee's report anticipated many of the legal, ethical, economic, social, medical, and policy aspects of genetic screening. The recommendations are current, and future committees should be familiar with them and not reinvent the wheel. If the Committee's recommendations had been implemented on time there would be a federal agency already in existence, responsive and responsible to carry out and support research on various aspects of genetic screening including implementation. Laboratories would have been in place and both the medical profession and the public would have been better informed and their knowledge of genetics would have proven of great benefit in their decision making process. Furthermore, today there would be a more adequate number of genetic counselors. Biotechnology is advancing rapidly and time should not be lost in setting up more committees. For example, the Secretary's Advisory Committee on Genetics, Health and Society is established to provide a forum for expert discussion and deliberation and the formulation of advice and recommendations on the range of complex and sensitive medical, ethical, legal, and social issues raised by new technological developments in human genetics [3]. Most of these issues have been considered by the SIEM Committee. Instead of continuously forming committees and commissions, there should be a federal agency as shown in figure 1 to carry out the work on a continuous basis.

The Committee anticipated the issues that may emerge with mandatory screening and recommended that participation in a genetic screening program should not be made mandatory by law; for states considering mandatory genetic screening the Committee recommended the examination of a law creating a Board on Hereditary Disorders. The Committee also anticipated the issues that might arise in screening for diseases for which there is not treatment and recommended that it is important that screening be used to study the natural history of genetic disorders for which there is no treatment at this time', but 'particular effort must be exerted to protect individuals identified by such screening against the psychological and social hazards that attend screening programs, but where impact may be enhanced by the lack of an effective treatment'.

Genetics has gained prominence and captured the interest and consideration of both the scientific community and the public. The discovery of enormous genetic variation and the implications of this variation for deciphering the genetics of complex diseases and personal traits have led to the development of a technology that 
scans for hundreds of thousands of genetic differences at once, linking particular variations to particular traits and diseases in ways not possible before. There are an estimated 15 million loci along the human genome where one base can differ from one person or population to the next. More than a dozen genome-wide association studies have been published this year. New technologies that are lowering the costs of sequencing and genome analysis will make possible the simultaneous genome-wide search for SNPs and other DNA alterations in individuals. Watson and Venter had their genomes analyzed, but we have yet to fully know the degree to which DNA differs from one person to another or the function of the genes involved in chronic disease development. With all these discoveries in human genetics a new industry developed: personal genomics. Depending on how much you can afford to spend, you can either buy a rough scan of your genome or have the whole genome sequenced. Industry feels that the information will help customers learn about themselves and by this way improve their health. But researchers worry that these services open up a Pandora's box of ethical, legal, behavioral, and social issues.

Studies on pharmacogenetics and pharmacogenomics, nutrigenetics and nutrigenomics have led to concepts of personalized medicine and personalized nutrition. Genome association studies aim to identify the genetic variants associated with chronic diseases in the hope of being able to screen individuals and populations at risk for cardiovascular disease, diabetes, cancer, and other chronic diseases for their prevention and management. The issues involved in these studies again are scientific, medical (safety and efficacy) economic, ethical, legal, social, and behavioral. The deliberation of the SIEM Committee and its recommendations are therefore applicable to today's concerns of genetic screening. The time has come to move on and establish a federal agency to deal with the development of genetic screening programs for early identification of the individual at risk. We must act quickly and strategically along with industry. Industry is already screening individuals for genetic variants for coronary heart disease, diabetes, and other chronic diseases. I believe this is premature because although there are genes indentified or associated with coronary heart disease or diabetes, we do not know if these individuals harbor protective genes or if the interaction of the gene with certain environmental factors such as diet or physical activity may blunt or precipitate the expression of genes that lead to or prevent disease. The SIEM Committee discussed a number of conditions or safeguards that need to be implemented following genetic screening such as the need for providing services, genetic counseling, etc. The issue of privacy and preventing discrimination (by health insurance) were thoroughly discussed by the committee. There is no need to repeat them. Today, genetic screening will require more extensive regulatory safeguards for efficacy and safety and at present the federal government has not yet moved to establish such programs. The existing programs for genetic screening - newborn genetic programs - will have to be modified in order to serve as a basis for the early identification of the individual at risk for chronic diseases. There is a need for a thoughtful establishment of programs that will expand genetic education in medical schools, schools of nursing, genetic counseling departments, and complete re-evaluation of the programs in schools of public health. Genetics affects not only the individual but the relatives. Genetic screening discovers something within a person's own make-up that may threaten his/her self-esteem or cause him/her to feel guilty of transmitting some 'blight' to his/her children. This causes special social, ethical, and legal questions having to do with consent, privacy, confidentiality, and labeling.

The infectious disease model is not adequate for public health genomics. Genetic screening programs must be voluntary and not mandatory. Buzz words such as personalized medicine and personalized nutrition have captured the imagination of physicians, industry, and the general public but several barriers impede their success.

There is no mechanism to ensure that genetic tests are supported by adequate evidence before they are marketed or that marketing claims for such tests are truthful and not misleading. Misleading marketing claims are particularly troubling when tests are sold directly to consumers, because there is no healthcare provider to serve as a 'gate keeper' to prevent inappropriate test ordering or misinterpretation of test results and to assure follow-up with genetic counseling and appropriate management.

Today, deciphering human genetic variation and the way genetic variants interact with environmental factors (nutrition, physical activity, etc.) to influence health is one of the most pressing goals for scientists to unravel and understand the underlying causes of common diseases. The new technology has shown that human beings are storehouses of genetic variability much more than ever anticipated. All kinds of genetic tests including 'direct to consumer testing' have been developed for screening, and dietary recommendations are being made in the absence of evaluation of efficacy of the tests. The American Society of Human Genetics and other societies have developed statements urging that more research is needed before dietary or medical advice is given [4]. Now more than ever 
there is a need for a federal agency or commission to build on the recommendations of the report of the SIEM Committee and to deal with the issues that have resulted from advances in overall biotechnology, informatics, DNA technology, throughput, biobanks, etc. [5]. It is necessary that the medical, legal, ethical, social, and economic aspects are considered as current screening tests are being developed. It is essential to keep in mind that the success of screening programs depends upon public acceptance and informed consent depends on adequate knowledge and understanding. If genetic screening is to play any significant part in preventive medicine or personalized medicine and nutrition, it will be because the public knows and understands its aims and impact and because physicians approve of it and advocate it. Conditions for screening are most favorable when a test is easy to do, reliable, inexpensive, and capable of automation.

Screening programs are typically undertaken for humanitarian and not economic reasons. The evaluation of such activities however involves a consideration that can serve to focus analysis on the means whereby the costs and benefits associated with the program can be evaluated. Genetic screening is carried out to find persons with particular genotypes in order to fulfill such traditional medical objectives as the provision of care for people who are sick and the prevention of disease. There are unacceptable aims for screening, for example there are no legitimate non-scientific aims of genetic screening. Screening should be offered to people as a service to them and no pressure should be applied to persuade them to cooperate out of sense of public duty. Political and eugenic ends must be excluded and it should be recognized that genetic screening does not aim for the perfectibility of human beings. It is merely one among many other uses of medical knowledge to improve the adaptive state of genetically threatened persons and to prevent needless suffering and human and economic waste. Rigorous safeguards are required to prevent its perversion to selective discrimination for any other than generally accepted medical or scientific reasons or for such illusory goals as the betterment of human beings.

President George W. Bush signed the Genetic Information Non-Discrimination Act (GINA) on May 21, 2008.

\section{Appendix}

The National Research Council Committee for the Study of Inborn Errors of Metabolism: Barton Childs, M.D., Chairman Professor of Pediatrics, The John Hopkins University School of Medicine, Baltimore, MD; Artemis P. Simopoulos, M.D. - Staff -
Project Director - Acting Executive Secretary, Division of Medical Sciences, Assembly of Life Sciences, National Research Council, Washington, DC; Robert A. Burt, J.D. Professor of Law and Law in Psychiatry, The University of Michigan, Ann Arbor, MI; Alexander Capron, LL.B., Assistant Professor of Law, University of Pennsylvania Law School, Philadelphia, PA; Joseph D. Cooper, Ph.D., Professor of Political Science, Howard University, Washington, DC; Charles J. Epstein, M.D., Professor of Pediatrics and Biochemistry, University of California, San Francisco, CA; Donald S. Fredrickson, M.D., President, Institute of Medicine, National Academy of Sciences, Washington, DC; Neil A. Holtzman, M.D., Associate Professor of Pediatrics, The Johns Hopkins University School of Medicine, Baltimore, MD; Cyrus Levinthal, Ph.D., Professor of Biology, Columbia University, New York, NY; Orlando J. Miller, M.D., Professor of Human Genetics and Development and of Obstetrics and Gynecology, Columbia University College of Physicians and Surgeons, New York, NY; Arno G. Motulsky, M.D., Professor of Medicine and Genetics, University of Washington School of Medicine, Seattle, WA; Robert F. Murray, Jr., M.D., Professor of Pediatrics and Medicine, Howard University College of Medicine, Washington, DC; Irwin M. Rosenstock, Ph.D., Chairman, Department of Health Behavior and Health Education, The University of Michigan School of Public Health, Ann Arbor, MI; David Rosenthal, Ph.D., Chief, Laboratory of Psychology, National Institutes of Mental Health, Rockville, MD; William J. Schull, Ph.D., Professor of Population Genetics, Graduate School of Biomedical Sciences, University of Texas Health Science Center, Houston, TX; Charles R. Scriver, M.D., C.M., Professor of Pediatrics, McGill University, Montreal Children's Hospital Research Institute, Montreal, Canada.

\section{References}

1 Simopoulos AP, Childs B: Committee for the Study of Inborn Errors of Metabolism, Division of Medical Sciences, Assembly of Life Sciences, National Research Council: Genetic Screening: Programs, Principles, and Research. Washington, DC: National Academy of Sciences, 1975.

2 National Information Resource on Ethics and Human Genetics. Washington, DC: National Reference Center for Bioethics Literature, Kennedy Institute of Ethics, Georgetown University, http://www.georgetown. edu/research/nrcbl/nirehg.htm.

3 Secretary's Advisory Committee on Genetics, Health, and Society (SACGHS), 'U.S. System of Oversight of Genetic Testing: SACGHS' Draft Response to the Charge of the Secretary of HHS'. National Institutes of Health (NIH), Bethesda, MD, 2007.

4 American Society of Human Genetics releases policy statement on direct-to-consumer genetic testing. American Society of Human Genetics Press Release, August 15, 2007. http://www.ashg.org/pdf/ASHG\%20 Releases\%20DTC\%20Genetic\%20Testing\% 20Statement $\% 20-\% 208.15 .07 . p d f$.

5 Scientists launch big genetic database project. UK Biobank, to hold millions of DNA samples, data. MSNBC News, March 14, 2006. http://www.msnbc.msn.com/id/ 11821298/from/RSS/. 